\title{
O CONCEITO DE AMÉRICA LATINA: UMA VISÃO FRANCESA*
}

\author{
Dilma Castelo Branco Diniz ${ }^{* *}$
}

Resumo: Este texto tem o objetivo de esclarecer o significado e a história do conceito de América Latina, descrevendo o seu nascimento, na segunda metade do século XIX, seu apogeu, no inicio do século XX e suas principais modificações ocorridas depois de 1945, dentro de uma perspectiva francesa.

A expressão "América Latina", apesar de ser de uso corrente na maior parte dos países do mundo e na nomenclatura internacional, apresenta uma definição precária. Marcada sobretudo pela diversidade, essa região aparece muitas vezes de modo indistinto, em função de uma aparente homogeneidade, que é percebida através da herança espanhola e portuguesa. Este estudo tem o objetivo de tentar esclarecer o significado e a história desse conceito, a partir do seu surgimento no século XIX. Retomarei aqui os trabalhos de Alain Rouquié e de Guy Martinière.

\footnotetext{
* Recebido para publicaçāo em juilho de 2007.

** Professora da Faculdade de Letras/UFMG.
} 


\section{A DIFÍCIL DEFINIÇÃO}

Como já nos alertou Alain Rouquié (1998, p. 15), o próprio conceito de "América Latina" é problemático. Do ponto de vista geográfico, o que se entende por América Latina? O conjunto dos países da América do Sul e da América Central? O México ficaria, portanto, de fora, já que, segundo os geógrafos, pertence à América do Norte. Para simplificar, poderíamos englobar, nessa denominação, os países localizados ao sul do rio Bravo. Seria preciso, então, admitir que a Guiana Inglesa e Belize, países de língua inglesa, e o Suriname, onde se fala o neerlandês, fazem parte da América Latina. Entretanto, se considerarmos que se trata de um conceito cultural, a definição reuniria exclusivamente as nações de cultura latina da América. Mesmo assim, haveria problemas. Com esse raciocínio, a província canadense do Quebec e Porto Rico - Estado livre associado aos Estados Unidos - seriam incluídos no bloco latino-americano, o que normalmente não é aceito.

Por outro lado, poder-se-ia pensar em descobrir uma identidade subcontinental forte, ligada por traços de solidariedade diversos, sejam eles provenientes de uma cultura comum ou de qualquer outra natureza. Mas a própria História dessas nações e sua grande diversidade cultural viriam contrariar essa justificativa. Durante mais de um século de vida independente, essas nações viveram isoladas, pouco se importando umas com as outras, mais interessadas em suas relações com a Europa e com os Estados Unidos. Além disso, há uma enorme disparidade entre os países, tanto em relação ao seu tamanho e potencial econômico quanto a seu papel regional. Desse modo, não houve o surgimento de uma consciência unitária entre eles. 
É por isso que alguns intelectuais latino-americanos, como, por-exemplo, Luis Alberto Sánchez e Leopoldo Zea, se questionam sobre a própria existência da América Latina, sem fornecer entretanto uma resposta definitiva. (ROUQUIÉ, 1998, p. 16). Outra conseqüência da constatação da existência de uma pluralidade, nas chamadas sociedades latino-americanas, foi a decisão de se tomar a denominação no plural - "Américas latinas". (Cf. NIEDERGANG, 1962). Se essa denominação apresenta a vantagem de reconhecer uma de suas dificuldades, acentua entretanto a sua dimensão cultural, que é também problemática.

Por que "latina"? De onde vem essa etiqueta, amplamente aceita na atualidade? Diante de certos fatos sociais e culturais, tem-se dificuldade em reconhecer essa propalada latinidade. Seriam latinas as Américas negras descritas por Roger Bastide? Seria latina a Guatemala, cuja metade da população descende dos maias e fala línguas indígenas? Ou o povo equatoriano, falante do quéchua? Latino, o Paraguai guarani, o estado de Santa Catarina, no Brasil, povoado por alemães, bem como o sul do Chile? De fato, essa denominação, relativa a formações sociais múltiplas e diversificadas, refere-se diretamente à cultura dos conquistadores e colonizadores espanhóis e portugueses. Assim, compreende-se melhor os espanhóis e outros latino-americanos que preferem a expressão América hispânica, ou mesmo Ibero-América, para não deiixar de fora o Brasil.

Essas considerações são importantes para destacar que o conceito de América Latina não é totalmente cultural nem somente geográfico. E dessa maneira, o termo mostra seus limites e ambigüidades: a América Latina existe, mas somente por oposição à América Anglo-saxônica. 
Alain Rouquié também afirma que os "latinoamericanos", enquanto categoria, não representam nenhuma realidade tangivel além de vagas extrapolações ou generalizações frágeis. Isso significa igualmente que o termo possui uma dimensão oculta que completa sua acepção. (1998, p. 16).

Dois outros atributos estão ainda ligados à América Latina: a sua situação sócio-econômica periférica, em relação ao "centro" desenvolvido, e o fato de pertencer à cultura ocidental. Nesse sentido, é curiosa a expressão usada por Riquié "Extremo-Ocidente", numa clara analogia a "ExtremoOriente".

Num estudo sobre o conceito de América Latina, importa verificar como, quando e porque surgiu e se afirmou essa "latinidade" do Novo Mundo.

\section{O NASCIMENTO DE UM CONCEITO}

$O$ pesquisador e historiador francês Guy Martinière nos revela o nascimento e o longo caminho percorrido pelo conceito que ele denominou "latinidade" da América (1982, p. 25-38).

No início do século XIX, sob a influência dos novos Estados Unidos da América e das idéias da Revolução francesa, surgiram as primeiras nações independentes, no chamado Novo Mundo. Martinière comenta que, em 1826, Alexander Humboldt escreveu em seu Essai politique sur l'île de Cuba:

"Pour éviter des circonvolutions fastidieuses, je continue à décrire dans cet ouvrage, malgré les changements politiques survenus dans l'état des colonies, les pays habités par les Espagnols- 
Américains sous la dénomination d'AmériqueEspagnole. Je nomme Etats-Unis, sans ajouter de l'Amérique septentrionale, les pays des AngloAméricains, quoique d'autres Etats-Unis se soient formés dans l'Amérique méridionale. Il est embarrassant de parler de peuples qui jouent un grand rôle sur la scène du monde, et qui n'ont pas de noms collectifs. Le mot Américain ne peut plus être appliqué aux citoyens, seuls des Etats-Unis de l'Amérique du Nord, et il serait à désirer que cette nomenclature des nations indépendantes du Nouveaú-Continent pût être fixée d'une manière à la fois commode, harmonieuse et précise." (MARTINIĖRE, 1982, p. 26) ${ }^{1}$

Mas foi preciso esperar ainda trinta anos, para que essa "maneira cômoda, harmoniosa e precisa" de definir coletivamente as jovens nações independentes da América colonizada pelos países ibéricos pudesse ser criada.

Essa nova invenção da América nasceu na Europa, mais precisamente na França, sob o Segundo Império. E esse

1 Para evitar circunvoluções fastidiosas, continuo a descrever nesta obra , apesar das mudanças políticas ocorridas no estado das colônias, os países habitados pelos espanhóis-americanos sob a denominação de América Espanhola. Nomeio Estados Unidos, sem acrescentar da América setentrional, as terras dos angloamericanos, embora outros Estados Unidos tenham se formado na América meridional. É embaraçoso falar de povos que exercem um grande papel na cena do mundo, e que não têm nomes coletivos. $O$ termo americano não pode mais ser aplicado somente aos cidadãos dos Estados Unidos da América do Norte, e seria desejável que essa nomenclatura das nações independentes do Novo Continente pudesse ser fixada de maneira, ao mesmo tempo, cômoda, harmoniosa e precisa. (A tradução é minha, assim como as outras que se seguem). 
novo batismo pode ser considerado quase tão importante quanto foi o primeiro, no século XVI, em que o geógrafo Waldseemuller designou América, do nome de Américo Vespucci, ao continente descoberto por Cristóvão Colombo. Data, portanto, do início da segunda metade do século XIX, o surgimento da expressão "América Latina". Diversas razões políticas e ideológicas estão na base dessa nomenclatura.

$O$ conceito de América Latina, criado na França durante o império de Napoleão III, nasceu pouco antes da expedição militar — e científica — francesa - e européia - ao México. Uma das primeiras obras impressas em Paris, talvez a primeira, a utilizar o conceito de América Latina foi a de Charles Calvo, obra monumental por sua dimensão (20 volumes de 400 a 500 páginas cada um), intitulada Recueil Complet des Traités $^{2}$, cujos primeiros volumes saíram no princípio de 1862.

O autor era latino-americano de origem e possuía grande reputação científica, participando de diversos grupos científicos franceses, além de virtudes políticas. Ocupava ainda o posto de "Chargé d'Affaires du Paraguay", junto às cortes da França e da Inglaterra. Sua obra foi dedicada ao próprio Imperador, com o objetivo, político e ideológico, bem definido: "Votre Majesté Impériale est le souverain de l'Europe qui a le mieux compris toute l'importance de l'Amérique latine, et celui qui a contribué de la manière la plus directe à l'immense développement du commerce que fait la France avec ce vaste continent." (MARTINIÈRE, 1982, p. 27-28)

2 A referência completa dessa obra é: CALVO, Charles. Recueil complet des traités, conventions, capitulations, armistices et autres actes diplomatiques de tous les Etats de l'Amérique latine compris entre le golfe du Mexique et le cap Horn depuis l'année 1493 jusqu'à nos jours précédé d'un mémoire sur l'état actuel de l'Amérique, des tableaux statistiques, d'un dictionnaire diplomatique avec une notice historique sur chaque traité important. Paris:Librairie A. Durand, 1862-1864, 20 vol.

3 Vossa Majestade Imperial é o soberano da Europa que melhor compreendeu toda a importância da América Latina, e aquele que contribuiu de maneira 
Alguns dias depois, o Ministro das Relações Exteriores, Thouvenel, lhe respondia que o Imperador... aceitava com prazer a dedicatória de um trabalho cuja publicação lhe parecia oferecer, naquela ocasião, um verdadeiro interesse. Ora, fazia poucos meses que as tropas francesas haviam desembarcado no México para derrubar Juarez, e perto de seis meses que a intervenção militar comum da Inglaterra, da Espanha e da França tinha sido decidida. Poderia haver melhor garantia do valor da política de Napoleão III na América Latina do que um texto científico do eminente diplomata latino-americano? É bem verdade que Charles Calvo se defendia em sua obra - uma página perdida entre milhares de outras - de ser favorável a uma intervenção armada no México. Entretanto, o mais importante ficava: sua definição "latina" do brilho político, cultural e econômico da França de Napoleão III em relação à América antigamente colonizada pela Espanha e por Portugal correspondia admiravelmente ao "grande desígnio" do Imperador.

Esse grande desígnio que, aliás, já havia sido refletido e posto em prática, há alguns anos, foi analisado pelo ideólogo oficial do regime imperial, o senador Michel Chevalier, no livro Le Mexique ancien et moderne, de 1863. Guy Martinière resume assim a análise de Chevalier:

"La France, héritière des nations catholiques européennes, porte en Amérique et dans le monde le flambeau des races latines, c'est-à-dire française, italienne, espagnole et portugaise. Gage de paix et de civilisation, ce flambeau permet d'autant mieux d'éclairer la marche dans la voie du progrès qu'une "concorde effective"

mais direta ao enorme desenvolvimento do comércio que faz a França com esse vasto continente. 
existe entre Paris et Londres. Cependant, si l'on n'y prend pas garde, le déclin qui a frappé l'Italie, l'Espagne et le Portugal, bref les nations catholiques et latines d'Europe, risque de s'accentuer au profit des nations chrétiennes dissidentes - Russie, Prusse et Turquie -à moins que, sous la houlette de Napoléon III, une nouvelle alliance ne les régénère. Car par delà les mers, de l'Atlantique au Pacifique, la montée des nations protestantes et de la race anglo-saxonne est d'autant plus évidente qu'en Amérique, ni le Brésil ni Cuba, ne sont, seuls, en mesure de contrebalancer l'influence des États-Unis. Il est donc largement temps de s'unir en Europe pour aider les nations latines, soeurs d'Amérique, à trouver cette voie du progrès que la France a découverte pour elle-même et soutenir efficacement d'abord le Mexique pour endiguer l'expansion des États-Unis." (MARTINIÊRE, 1982 , p. 28-29) ${ }^{4}$

4 A França, herdeira das nações católicas européias, conduz na América e no mundo o facho das raças latinas, isto é, francesa, italiana, espanhola eportuguesa. Penhor de paz e de civilização, esse facho permite melhor aclarar a marcha na via do progresso visto que uma "concórdia efetiva" existe entre Paris e Londres. Entretanto, se não se usa de precaução, o declínio que afligiu a Itália, Espanha e Portugal, em suma as naçōes católicas e latinas da Europa, corre o risco de acentuar-se em benefício das nações cristãs dissidentes - Rússia, Prússia e Turquia - a não ser que, sob a proteção de Napoleão III, uma nova aliança os regenere. Porque além dos mares, do Atlântico ao Pacífico, a escalada das naçōes protestantes e da raça anglo-saxônica é mais evidente na América, visto que nem o Brasil nem Cuba sozinhos estão habilitados para contrabalançar a influência dos Estados Unidos. É, portanto, plenamente tempo de se unir na Europa para ajudar as nações latinas, irmãs da América, a encontrar essa via do progresso que a França descobriu por si mesma e sustentar, eficazmente, primeiro o México para conter a expansāo dos Estados Unidos. 
Percebe-se, portanto, que essa ideologia latina de Napoléon III, além de interesses próprios, visava a conter o expansionismo dos Estados Unidos. Martinière afirma que o nome "América Latina" não aparece na obra de Michel Chevalier nem nas pretensões do Imperador dos franceses. Tratava-se somente das raças latinas da América. Mas a utilização feita por Charles Calvo da nomenclatura de América Latina, que faltava a Humboldt, não tardaria a ser amplamente empregada.

Como era de se esperar, as primeiras reaçṍes favoráveis e desfavoráveis - em relação a essa nomenclatura provocaram longos e violentos debates políticos eideológicos em torno da estratégia francesa de intervenção em solo americano.

O apoio "cultural" das nações latinas e católicas da Europa foi muito discreto, tirando os meios favoráveis à França nas penínsulas mediterrâneas. Para a Espanha, que tinha aversão em reconhecer a independência das antigas colônias, os Estados da América eram, primeiramente, hispano-americanos antes de ser latino-americanos. E a noção de hispanidade não tardaria a aparecer em resposta a essa latinidade. Da mesma forma, Portugal se volta para seu império lusitano da África e da Ásia, considerando o Brasil suficientemente "maior" para empreender seu próprio vôo. Quanto à Itália, os ânimos estavam muito preocupados com a formação da unidade nacional e com o papel que Napoléon III poderia exercer, nesse contexto, para se interessar pelo continente latino da América.

A expressão América Latina foi ainda muito contestada na Alemanha, pelos discípulos de Humboldt. Um certo Wappaens declarou, num jornal de Goettingen, em 1863, que os hispano-americanos, em vez de seguir as teorias francesas, deveriam voltar-se para a Espanha; e em vez de enviar 
estudar na França, deveriam enviá-los às universidades espanholas e se inspirar na literatura espanhola, em vez de tomar suas idéias nos escritos de Voltaire, Rousseau, Eugène Sue e outros franceses semelhantes. (MARTINIÈRE, 1982, p. 29-30).

Apesar de toda essa polêmica, de fato, foi nos meios intelectuais das jovens nações independentes da América que a expressão América Latina foi aceita e reivindicada com o maior vigor. Ela permitia, enfim, aos antigos colonizados sair da tutela da mãe pátria ibérica e obter um estatuto internacional independente. Este seria, pois, o significado da francofilia entre os latino-americanos: "construir sua autonomia cortando o cordão umbilical ibérico e identificando-se simbolicamente com o modelo francês, bastante diferente para permitir a ruptura, bastante semelhante para permitir a identificação simbólica" (RIVAS, 2001, p. 99).

Convém lembrar que a estratégia aventurosa de Napoléon III, com sua expedição militar ao México, quase comprometeu o impacto cultural da latinidade da América. Mas Guy Martinière afirma que o sucesso definitivo do conceito de América Latina foi obra ideológica da Terceira República (1982, p. 30-31). A derrota de Sedan, na Guerra franco-prussiana, marcou o fim do Segundo Império e o início da III República; e o revés lamentável da expedição ao México tornou-se o presságio da catástrofe militar do Império. Entretanto, os êxitos do período imperial, sobretudo em matéria econômica, como foi o caso da revolução industrial, foram considerados uma herança pelos adeptos do novo regime. Dentro do mesmo espírito, a herança do "conceito" de América Latina, apesar do erro colonial de Napoléon III, foi também reivindicada, procurando reconquistar esse mundo recém-libertado. Mas depois da queda do Imperador, 
o conceito de América Latina foi empregado na França com. muita reserva. Marcado pelo erro napoleônico, não seria mais conveniente bani-lo das memórias, assim como o conjunto da obra política imperial?

Apesar disso, o sucesso obtido por esse tema na própria América e a política cultural e econômica favorável à França que o sustentava fez com que a expressão se tornasse, a partir de 1880-1885, de uso cada vez mais corrente.

Importa esclarecer que, com o passar do tempo, novos significados foram dados a essa latinidade. Primeiro, o caráter católico da herança latina foi suprimido. Esse desaparecimento coincidiu com a emergência de um positivismo de combate, filosofia que se tornou a ideologia oficial da República laica de Jules Ferry. Ora, a doutrina positivista, propagada pelos discípulos de Auguste Comte, tinha feito adeptos na América Latina, conquistando o México rebelde dos herdeiros de Juarez e também o Brasil, que logo depois derrubou o seu governo imperial. As repúblicas da América se tornaram assim repúblicas latinas, "irmãs" da grande República francesa que guiava o mundo em direção à Civilização e ao Progresso. Vale lembrar que a divisa de nossa bandeira, "Ordem e progresso", é tipicamente positivista.

Os conflitos militares do início do século $X X$ acentuaram essa orientação. Com a Primeira Guerra mundial, alcança seu ponto culminante, na visão estratégica ideológico-cultural das classes dominantes francesas e sul-americanas, essa concepção de uma civilização latina, verdadeiro eixo leste-oeste, símbolo de um prolongamento da Europa humanista, herdeira do mundo greco-latino, em direção a esse Novo Mundo tão rico de futuro que constituíam as Repúblicas latinas da América.

Foi tão grande o impacto de sua influência nos Estados Unidos que chegou a se traduzir numa visão panamericana do 
continente. Mesmo assim, o conceito de América Latina foi admitido e empregado correntemente pelos estadunidenses. A expansão do panamericanismo no eixo norte-sul, confrontando-se com as fronteiras do latino-americanismo, não conseguiu vencer, sobre o plano cultural, o declínio da Europa, nem mesmo depois da queda da "influência francesa" na América Latina, entre as duas guerras mundiais. Adotando essa nomenclatura e defendendo-a, as elites crioulas da América, que haviam rejeitado a dominação política dos países ibéricos, proclamaram assim sua originalidade diante da expansão do imperialismo ianque. O enxerto da lạtinidade havia vencido...

\section{A AMÉRICA LATINA DEPOIS DA SEGUNDA GRANDE GUERRA}

Outras terminologias haviam sido utilizadas para definir a originalidade dessa área cultural. América ibérica ou América espanhola e portuguesa continuaram a ser empregadas; América amerindia foi também proposta, mas não foi bem aceita. Afinal, qual foi o papel dos índios na elaboração da consciência nacional que as classes dominantes crioulas forjaram?

Em relação aos geógrafos franceses, houve, durante muito tempo, uma recusa em utilizar o nome de América latina, terminologia que apresentava ressonâncias ideológicas e culturais precisas. Preferiram as denominações mais neutras de América do Sul e América Central. Mas parecia artificial isolar o México desse conjunto ao qual estava ligado. Afinal, em 1973, publicaram a primeira obra coletiva consagrada a uma Geografia da América Latina, com prefácio de Pierre Monbeig (COLLIN-DELAVAUD, 1973). ${ }^{5}$

5 Pierre Monbeig e Fernand Braudel fizeram parte do grupo de professores franceses da USP, nos anos trinta, ao lado de Claude Lévi-Strauss, Paul Arbusse- 
Logo depois da Segunda Grande Guerra, os historiadores franceses começaram pouco a pouco a usar o termo no plural: Amériques latines, em vez de América Latina. Guy Martinière nos conta que Fernand Braudel foi o primeiro a colocar esta questão, a partir de 1948, num artigo de título provocador: "Existe uma América Latina?". Esse artigo retomava a obra homônima do autor peruano Luis Alberto Sanchez e sua conclusão era firme: "na verdade, a América Latina só é uma, nitidamente, vista de fora... Ela é uma por contraste, por oposição, tomada em sua massa continental, mas com a condição de se opor a ela os outros continentes, sem que isso não a impeça de ser profundamente dividida" (1982, p. 32) ${ }^{6}$. Esse quarto número dos Cahiers des Annales, em que foi publicado o artigo de Braudel, continua Martinière, (1982, p. 38) tinha um título que constituía um verdadeiro programa de ação e pesquisa: "A travers les Amériques latines". Pela primeira vez, o plural era utilizado. E quando o Institut des Hautes Études de l'Amérique latine decidiu publicar regularmente uma revista, em 1968, o título escolhido foi Cahiers des Amériques latines. Seria a melhor maneira, segundo Pierre Monbeig, de se interrogar, com a maior eficácia possível, sobre o "destino das Américas Latinas".

Dessa maneira, criava-se um novo conceito operatório, logo depois da Segunda Grande Guerra, a partir do conhecimento íntimo das realidades. Depois de muitos anos de estudo e pesquisas efetuadas em vários países da América

Bastide e outros. Cf. TRINDADE, Hélgio. "Ciências Sociais: Instituições e Atores Estratégicos no Intercâmbio Franco-Brasileiro". In: MARTINS, Carlos B. (Org.) Diálogos entre o Brasil e a França: formação e cooperação acadêmica. Recife: FJN, Ed. Massangana, 2005. Edição bilingüe português-francês, 2 v. p.288.

- O artigo de Braudel foi publicado nos Cahiers des Annales n. 4. Paris, 1949 (numéro spécial d'octobre-décembre 1948 de la revue Annales - Économies Sociétés - Civilisations). 
Latina, principalmente no Brasil e no México, professores franceses propuseram o novo conceito. Vinte anos mais tarde, depois de numerosos debates, os primeiros resultados apareciam. E esse período de efervescência, que foi o ano de 1968, viu reconhecida, enfim, a nova nomenclatura.

Entretanto, a realidade está sempre em movimento; os debates prosseguem e novas idéias germinam no espírito de outros intelectuais. O historiador italiano Ruggiero Romano, em sua obra Les mécanismes de la conquête coloniale: les conquistadores, publicada em 1972, assim se expressou:

"Comment ne pas voir que la définition de latine ne couvre plus la réalité de l'Amérique centrale et méridionale? Personne n'oserait, et personne n'ose de fait, parler de la latinité de l'Amérique à l'époque coloniale: l'accord, à ce sujet, est complet. En revanche, pour la période qui s'étend du milieu du XIXe.siècle aux trente premières années du XXe. siècle, il existe un accord à propos de la définition latine: et, je le répète, il me paraît formellement juste. Les cadres du pays étant à ce moment-là de formation (et d'inspiration) essentiellementfrançaise, la définition estcorrecte ( même si l'on pense qu'à cette même époque de pleine latinité, la partie la plus importante et la plus agissante des intérêts en Amérique centrale et méridionale était d'origine anglo-saxonne...)" (MARTINIÈRE, 1982, p. 33-34) ${ }^{7}$

7 Como nāo ver que a definição de latina não cobre mais a realidade da América central e meridional? Ninguém ousaria, e ninguém ousa de fato, falar da latinidade da América na época colonial: o acordo sobre esse assunto é completo. Em compensação, para o período que se estende do meio do século XIX aos trinta primeiros anos do século $\mathrm{XX}$, há um acordo a propósito da definição 
Mas Ruggiero Romano conclui que, atualmente, há dois fenômenos concomitantes e às vezes opostos. De um lado, existe um despertar incontestável das massas americanas que, de maneira mais ou menos clara, intervêm no debate interior da América central e meridional. De outro lado, as classes dirigentes orientam-se em direção a formas de pensar e a estilos de vida provenientes dos Estados Unidos da América. Outro fenômeno, de menor importância, é constituído pelos grupos de oposição que recusam esquemas, ideologias, padrões vindos dos Estados Unidos ou provenientes da latinidade, para se orientar em direção a patrimônios culturais russos, chineses ou ...americanos...do Centro ou do Sul. Nessas condições, abandonar a definição latina seria prudente. Mas uma prudência que deveria vir apoiada por um imenso poder sobre a imprensa, o rádio e a televisão de todo o mundo. Esse poder, contudo, não pertence somente aos intelectuais... (Cf. ROMANO, 1972)

Haveria, pois, a necessidade de abdicar de toda referência à latinidade da América, mesmo depois de descobrir sua grande diversidade, através das Américas Latinas? A questão permanece, principalmente porque a conjuntura política dos anos 1970 deu ao debate uma outra dimensão.

Com efeito, em 1975, a incursão de Cuba na cena política africana provocou muitas surpresas. Numerosos observadores de política internacional vincularam rapidamente as ações dos cubanos na África ao expansionismo soviético: a política africana de Cuba aparecia como o "braço armado" de Moscou. Depois, com a ajuda ao movimento de Agostinho Neto, por

latina: e, repito, parece-me formalmente justo. As estruturas do país estando naquele momento de formação (e de inspiração) essencialmente francesa, a definição está correta (mesmo se se pensa que nessa época de plena latinidade, a parte mais importante e a mais ativa dos interesses na América Central e meridional era de origem anglo-saxônica...) 
ocasião da independência de Angola, e a intervenção na Etiópia, a pedido do coronel Mengistu, a política africana de Cuba foi muitas vezes assimilada somente à intervenção de combatentes armados.

Entretanto, esse aspecto fundamental da cooperação cubana na África constitui apenas uma faceta dos novos tipos de relações que se estabeleceram entre Cuba e a África. No domínio cultural, explica Guy Martinière, a emergência de um novo conceito operatório foi expressa por Fidel Castro em 1975: Cuba não se apresenta mais hoje como um país "somente" latino-americano, mas como um país latino-africano.(1982, p. 34). É evidente que esse novo conceito foi forjado com a finalidade de justificar ideologicamente uma intervenção armada conjuntural. Mas a emergência de tal conceito de latino-africanidade cubana reflete outras preocupações.

De fato, a descoberta política do continente africano por Cuba não data de 1975, mas é contemporânea da própria Revolução de 1959. O estabelecimento da cooperação cubana na África está, portanto, ligado estruturalmente à reavaliação radical da identidade cultural cubana, dessa cubanidad de raízes africanas fundamentais nascida da Revolução. $O$ modelo socialista instaurado em Cuba não afirma querer estabelecer um sistema de desenvolvimento voltado, primeiramente, para o povo e não, para as classes dirigentes crioulas?

Tanto em Cuba como em outros países da América Latina, continua Martinière, isso supõe a integração de todos os excluídos de uma economia de mercado dependente: classes dominadas e raças desprezadas dessa multidão colorida que forma a população das nações do Novo Mundo enfim reunidas num novo direito à identidade política.

A Revolução "socialista" cubana declara transformar a sorte desse povo, procurando acabar com todo traço de racismo 
existente na ilha, um racismo que se achava profundamente arraigado pela estratificação social da colonização espanhola e utilizado pelas classes crioulas em seu proveito. A literatura, a poesia e também as expressões folclóricas, como a dança (de modo especial a rumba), a música, a cozinha, a mestiçagem, a religião... são profundamente impregnadas dessas "raízes" africanas. Marginalizadas pela elite social branca, ou que se dizia branca, essas tradições populares são, a partir de 1959, objeto de um fervor "cultural" revolucionário. Se não se pode afirmar que as raízes "afro-cubanas" por si só explicam as formas da política de solidariedade de Cuba em relação à África, como não levá-las em conta numa análise da política africana de Cuba? Seguindo essas considerações, Guy Martinière ainda pergunta:

"Que signifiait, et que signifie encore, l'espérance symbolique du "sang noir des Tropiques" dans la tradition culturelle exprimée officiellement aujourd'hui à La Havane et qui trouve dans la doctrine marxiste une rationalité inattendue?

Que signifie ce "négrisme métissé" cher à Nicolas Guillén et Alejo Carpentier dans la réévaluation culturelle de la cubanidad?" (1982, p. 35$)^{8}$

Importa lembrar que esse fenômeno da afro-latinoamericanidade não se refere somente a Cuba. Integra, de

8 Que significava, e que significa ainda, a esperança simbólica do "sangue negro dos Trópicos" na tradição cultural expressa oficialmente hoje em Havana e que encontra na doutrina marxista uma racionalidade inesperada? Que significa esse "negrismo mestiço" caro a Nicolau Guillén e Alejo Carpentier na reavaliação cultural da cubanidad? 
certa forma, o movimento de revolta da negritude, que, nos anos 1930, restabeleceu os laços culturais entre a África e a América. São inúmeras as obras que tratam da mestiçagem e da negritude, mostrando a generalização dessas novas relações em toda a. América Latina. Outros países latino-americanos, inclusive o Brasil, traduzem sua africanidade a seu modo, sobretudo após a emergência do chamado "Terceiro-mundo", nos anos cinqüenta. E com a descolonização da África, houve a possibilidade de maior cooperação entre países latinoamericanos e africanos, tanto no domínio diplomático quanto comercial.

Guy Martinière comenta que os sistemas de referências de Cuba e do Brasil aparecem antitéticos, desde 1964, tanto no âmbito das escolhas de desenvolvimento quanto no das relações internacionais. Surge então uma oposição entre os comportamentos "cooperativos" de Cuba e do Brasil em relação à África: enquanto o Brasil dos mịlitares efetua, entre 1970 e 1973, uma abertura diplomática e comercial com a África austral branca, que parecia relativamente estável, Cuba "socialista" só podia estabelecer relações com certos países da África "progressista". Logo depois, com a queda do regime de Caetano, sob a influência do Movimento das forças armadas, em abril de 1974, houve o início da retirada dos portugueses da África, fato que deu origem a cinco novos Estados africanos. Para Cuba, foi a ocasião de sua reentrada fragorosa no continente negro. A luta pelo poder, no momento da proclamação da independência nacional desses Estados, conduziu a novas formas de cooperação com parceiros que não se contentavam mais com o quadro tradicional das relações entre a Europa e a África, até mesmo sob o ponto de vista cultural. (MARTINIĖRE, 1982, p. 36)

Embora exemplares, o caso do Brasil e de Cuba não são exceções dentro da nova cooperação africana. Existeminúmeros 
trabalhos que tratam da mestiçagem e da negritude, inclusive no caso do discurso antilhano, que provam a generalização desses novos laços. (Cf. GLISSANT, 1981). É o que acontece com as Américas negras, na feliz expressão de Roger Bastide, que encontram suas raízes africanas no conjunto do Novo Mundo. Até mesmo países pouco suspeitos de tradições africanas redescobrem sua africanidade, como mostra a obra de Denys Cuche sobre o Peru negro. Importa lembrar ainda que, na América andina e no México, a reivindicação dos descendentes dos indígenas já havia contribuído para se repensar numerosos aspectos dessa latino-americanidade triunfante.

Não se sabe datar exatamente os primeiros índícios de uma tomada de consciência ativa dos interesses comuns dos países latino-americanos. Mas pode-se observar, atualmente, um esforço de certos países no intuito de estabelecer uma maior integração com seus vizinhos, principalmente no âmbito das relações comerciais. É o caso da criação de blocos comerciais, como o Mercosul, por exemplo. Além disso, a globalização do comércio e a recusa de um mundo unipolar aproximaram também a América Latina de outros atores internacionais.

Entretanto, a continuidade cultural com a Europa se, por um lado, apresenta grande facilidade para as transferências científicas ou tecnológicas, por outro, pode também representar um atalho que freia o crescimento, estabelecendo, provavelmente, a forma mais sutil de dependência. Com efeito, o desenvolvimento da América Latina foi induzido do exterior e as distorções provocadas por esse tipo de crescimento são múltiplas: vulnerabilidade, dependência exterior, endividamento e ainda heterogeneidade social com o crescimento da desigualdade. Essa tensão social e mesmo racial se configura ao mesmo tempo como expressão de uma crise e uma característica essencial do perfil das sociedades latino-americanas, que se encontram na periferia ocidental do mundo desenvolvido. 
Résumé: Ce texte a pour but d'éclairer la signification et l'histoire du concept d'Amérique latine, en décrivant sa naissance dans la seconde moitié du XIXe. siècle, son apogée au début du XXe. siècle et ses principales modifications survenues après 1945, dans une perspective française.

\section{REFERÊNCIAS}

BASTIDE, Roger. Les Amériques noires. Les civilisations africaines dans le Nouveau Monde. Paris: Payot, 1967.

CHEVALIER, Michel. Le Mexique ancien et moderne. Paris: Hachette, 1863.

CUCHE, Denys. Le Pérou nègre. Paris: L'Harmattan, 1981.

COLLIN-DELAVAUD, Claude. (Dir.) L'Amérique latine. Approche géographique générale et régionale. Paris: Bordas, 1973, 2 v.

GLISSANT, Édouard. Le discours antillais. Paris: Seuil, 1981.

NIEDERGANG, Marcel. Les Vingts Amériques latines. Paris: Seuil, 1962.

MARTINIÈRE, Guy. L'invention d'un concept opératoire: la latinité de l'Amérique. In:___ Aspects de la coopération francobrésilienne. Grenoble; Paris: Ed. de la Maison des Sciences de 1'Homme, 1982. p. 25-38.

RIVAS, Pierre. Paris como a Capital Literária da América Latina. In: CHIAPPINI, L. \& AGUIAR, F. Wolf da (Orgs). Literatura e História na América Latina. São Paulo: EDUSP, 2001.

ROMANO, Ruggiero. Les mécanismes dela conquête coloniale: les conquistadores. Paris: Flammarion, 1972.

ROUQUIÉ, Alain. Amérique latine: introduction à l'ExtrêmeOccident. Paris: Seuil, 1998. 